\title{
E-Commerce Transition Model for Supply Chain Management
}

\author{
Louis A. Lefebvre, Luc Cassivi and Élisabeth Lefebvre \\ ePoly Centre of Expertise in Electronic Commerce, École Polytechnique de Montréal, P.O. Box 6079 succ. Centre-Ville, Montréal, \\ Canada, H3C 3A7 ; Tel : (514) 340-5860 ; Fax : (514) 340-5987 ; LouisA.lefebvre@epoly.polymtl.ca
}

\begin{abstract}
The creation of Internet-based companies is changing the way business is being carried out and increasing the pressure on traditional firms, which now need to adapt to the new challenges brought about by the so-called digital economy. Successful electronic commerce activities depend on the partners involved in the product or service being delivered. Firms able to communicate with their partners electronically for procurement, sales, or supply chain management have become what many call clicks-and-mortar companies.

An empirically based technological model that helps organizations understand the requirements of moving towards the seamless integration of intra- and inter- organizational processes is proposed. This five-wave transitional model accompanies key decision-makers through progressive steps that correspond to different business-to-business e-commerce needs and specifications. As organizations move along these technological waves, we can witness the gradual opening-up of new opportunities for carrying out business. This paper presents the model, its requirements and its technological and organizational underpinnings. The model is illustrated with examples from organizations in a major industrial sector.
\end{abstract}

Key word: electronic commerce, supply chain, technological requirements

\section{Introduction}

At the dawn of this new millennium, we are finally starting to witness the exponential growth of electronic commerce (e-commerce) that most specialists have been forecasting for the last few years. It is clear that the diffusion of electronic commerce will persist, and indeed accelerate, in the years to come. Five of the largest North American research firms have provided forecasts of the projected growth of Businessto-Business e-commerce (see appendix 1). As for the definition of "electronic commerce", there are several and they differ considerably. The OECD tackled the issue in its e-commerce work program initiative (OECD 1999) and came up with the following: "Electronic commerce refers generally to commercial transactions, involving both organizations and individuals, that are based upon the processing and transmission of digitised data, including text, sound and visual images and that are carried out over open networks or closed networks that have a gateway onto an open network" (OECD 1997).

Elsewhere, the Japanese Ministry of International Trade and Industry (MITI), which has been a strong promoter of supply chain integration, defines electronic commerce as "the conducting of commercial transactions (the exchange of merchandise, services, information, and/or money between suppliers and receivers for the commercial transfer of goods between economic actors) through electronic mediation using Internet technology" (MITI and Electronics Policy Division 1999).
Clearly, electronic commerce facilitates the exchange of information by developing stronger buyer-supplier relationships. Suppliers are no longer seen as potential competitors but as partners (PricewaterhouseCoopers 1999). Bakos and Brynjolfsson (1993) discuss the value-adding partnerships that have emerged with the new information technologies. These collaborations favour outsourcing to a smaller number of faithful suppliers. Indeed, Collins and Bechler conclude in their study that the outsourcing of manufacturing has become a competitive imperative and is now a strategic choice for most organizations (Collins and Bechler 2000). Furthermore, despite the increasing need for an integrated and flexible supply chain where the focus has shifted from push (forecast-driven) management to pull (demand-driven) management, long-term partnerships between manufacturers and suppliers have been more beneficial than arm's-length relationships in terms of quality, time to market, and product development (Collins and Bechler 2000; Groves and Valsamakis 1998; Handfield et al. 1999; Heikkilä and Vollmann 1999; HIDC 1998). The label Supply Chain Management (SCM) is currently being used to designate these activities: "It integrates planning and balances supply and demand across the entire supply chain - it ties suppliers and customers together in one concurrent business process that focuses on the ultimate customer" (Schorr 1998).

Cox et al. (2000) have analysed different types of buyersupplier relationships and are convinced that a buyer with a dominant position can and should exploit its situation to benefit the overall relationship (i.e. improve quality and 
reduce costs). These relationships are being promoted through the creation of major electronic platforms (or marketplaces) where large organizations are joining forces to increase their buying power. Four of the world's biggest defence and aerospace firms (Boeing, Raytheon, Lockheed Martin and BAE Systems) have pooled their resources and merged with Commerce One to form a Web-based marketplace for aerospace parts and services. The platform brings together 37,000 suppliers and a significant number of airlines in order to process $\$ 71$ billion in annual procurement expenditures. The automobile industry has been moving in a similar direction, with the likes of Ford, General Motors and DaimlerChrysler creating, in May 2000, a marketplace known as Covisint, along with new members Renault, Nissan and Toyota. This platform is expected to handle more than $\$ 750$ billion in transactions annually. This paper will look at some of the new business-to-business electronic commerce functionalities (transaction processes) that seem to be emerging between manufacturers and suppliers, with a special focus on the technologies required to support these e-commerce applications.

\section{Electronic commerce transaction processes}

Most of the business-to-business electronic commerce platforms that have emerged in the last year, or even months, in various industrial sectors have focused on catalogues, auctions and bidding systems. Most of these marketplaces plan on developing sophisticated technical and graphical exchange tools but very few have been able to market them effectively yet. The automobile and aeronautic platforms, along with more company-specific platforms such as GE's TPN system, are still dealing with basic transactional services. Others such as E-vis have developed collaborative design and engineering platforms that meet the needs of innovative firms in a niche market. These more advanced platforms will evolve in the years to come such that SMEs, which often have an important role in designing a product (up to $70 \%$ of a car or a plane), will have to learn to use these technologies and, most importantly, deal with them securely in order to transfer confidential and often very strategic information.

A comparative study conducted by the MITI in Japan and Andersen Consulting in the U.S. has identified the major B-to-B electronic commerce transaction processes carried out by organizations engaged in electronic commerce (MITI and Electronics Policy Division 1999). These e-commerce functionalities, shown in figure 1, will intensify in the years to come. Most of the electronic commerce functionalities singled out by the MITI study are procurement-oriented. Other reports and papers in procurement and electronic commerce identify similar activities (Industry Directions 2000; Smeltzer and Siferd 1998). This obviously raises some very fundamental questions with respect to e-commerce functionalities and their supporting technologies.
1) Order booking

2) Estimate prices from suppliers

3) Info on procured items \& product specifications

4) Delivery inquiries

5) Product shipping info

6) Negotiation of price. volume. etc.

7) Design and graphics exchange

8) Supplier registration application

9) Payment of funds

10) Supplier selection

11) Study of detail specs.

12) Initial contracts

13) Others

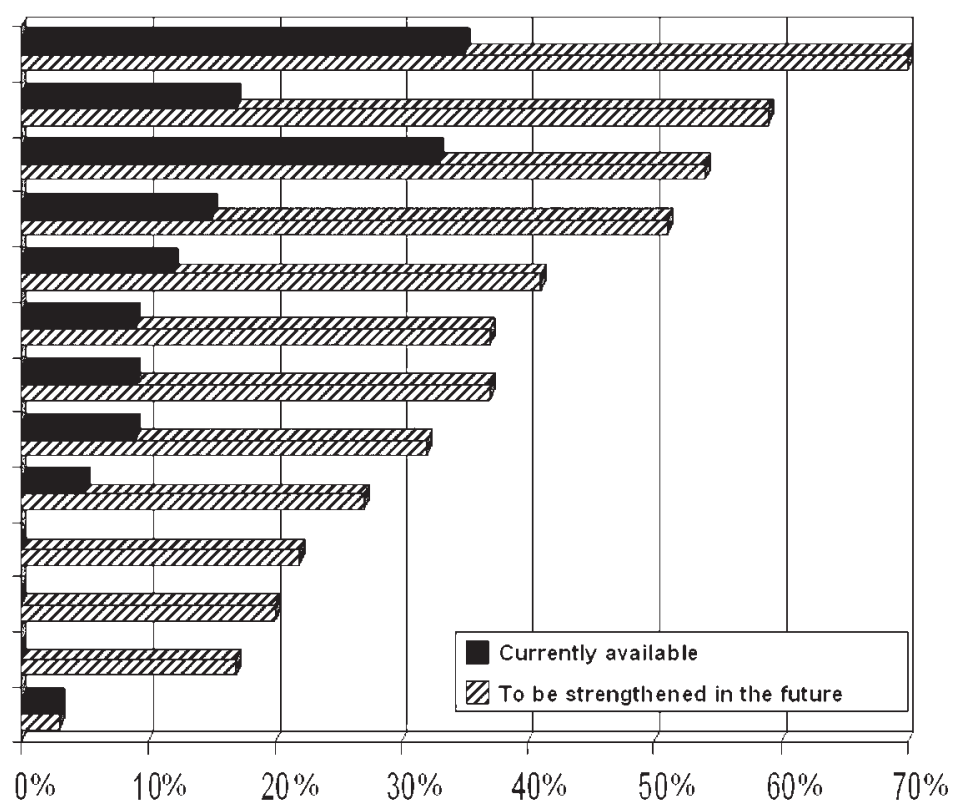

Figure 1. E-commerce functionalities.

Source: MITI and Andersen Consulting, Size of Market Study for Electronic Commerce, March 1999. 


\section{Research questions and methodology}

The organizations that will benefit from these initiatives are those that understand the needs and requirements of carrying out electronic commerce activities and how this will ultimately change the way business is conducted. In this paper, we will try to answer the following questions:

1. Are electronic commerce transaction processes crossfunctional within the organization? If so, which functions of a company (sales, marketing, manufacturing, design, etc.) are the most affected by organizational and technological changes?

2. What technologies are required to optimise the flow and management of information that supports e-commerce functionalities within and between organizations?

\section{Research design}

In order to answer these questions, we have combined three different methodological strategies that are briefly outlined below.

\section{Case studies}

First we have chosen a specific research design called "multiple-case embedded design" (Yin 1999). Several case studies seem highly preferable to one case study; based on the wide variety of SMEs, it appears highly improbable that SMEs may be subsumed under one unique revelatory case. Embedded case studies by definition involve more than one unit of analysis: different units of analysis appear more appropriate to thoroughly analyse the complex transition. Four widely differing SMEs were retained. The only common characteristic pertains to the fact that they are all from the electric/electronic industry and act as subcontractors for the same major client, a large public utility company.

The first SME operates in a traditional sector and specializes in high quality steel forgings. In-house melting, forging, heat-treating, machining, testing and inspection facilities provide the flexibility to produce a highly diversified range of forged products. It has over 50 years of forging experience and an excellent reputation, amongst the leaders in the open die forging industry.

The second SME is an affiliate of a large group of transformer companies. It provides transformers to all national and international standards and its product range includes liquid filled transformers for distribution, generator step-up, medium and large power substation, autotransformers, furnace, grounding, shunt and series reactors, and phase angle regulation.

The third SME is a high-tech company and a leading developer and manufacturer of precision monitoring and control devices for the electricity industry. It offers three types of products: condition-monitoring apparatus with expert system software for predictive maintenance of circuit breakers, point-on-wave command synchronizer for the activation of a circuit breaker at the optimum moment of the voltage cycle, and a portable automated system that eliminates the difficulty and tedium from capacitor-bank testing.

The fourth SME acts as a rather small job shop with 40 employees. Its main activities are precision machining, metal roll manufacturing and welded component manufacturing. It relies on strong engineering and manufacturing competencies to offer customized services to clients in different industries.

A rigorous protocol is essential for multiple-case design; in particular, field procedures, interview guides and specifications for the case study report were carefully established. Several different sources of evidence were used: written internal reports, data obtained from articles, and additional information gained from focused interviews with key managerial personnel within each firm. The indepth interviews in particular proved to be very a rich and valuable source of data. The analysis of data across multiple sites includes within-case and cross-case analysis, with the former being a prerequisite for the latter. In this section, we will present only the results of our cross-case analysis, which was performed using Glaser and Strauss's constant comparative method: this is particularly effective at discovering emerging patterns across cases (Miles and Huberman 1994). Frequent visits to these companies enabled us to identify the individuals (operators, technicians, buyers, etc.) who were most able to address very specific questions and to validate the answered questionnaires and the information collected during interviews. All of this was conducted over a three-year period, which allowed us to witness the gradual change, from the creation of web sites, to the implementation of ERPs (Enterprise Resource Planning), to the creation of electronic marketplaces. These in-depth case studies were determinant in understanding the evolving nature of technological requirements associated with the changing functionalities and applications of ecommerce.

\section{Simulations}

Second, simulations were conducted at ePoly in the Virtual Enterprise Laboratory of ePoly, which specializes in the development and simulation of advanced e-commerce applications. Its sophisticated technological infrastructure can integrate large software applications such as ERPs (SAP $\mathrm{R} / 3$ ) to VPDMs (Nexprise) and other e-commerce and software tools (Entrust Technologies, Profitkey RRM, Impress OIS, etc.). Deeper insights were therefore gained when simulating supply chain environments and product life cycle analysis platforms. 


\section{Technological scanning}

Third, constant monitoring activities were performed. Tracking of international norms and standards, along with the identification and analysis of e-commerce best practices were key activities in this process. A thorough literature review as well as constant interactions with our technology and research partners proved to be very useful inputs for this study (Lefebvre et al., 2001).

These three different methodological strategies led us to formulate a wave model, which is illustrated in figure 5.

\section{Validation of the transaction model}

The model was first developed to describe the evolution in technologies that would enable an organization to formulate an e-commerce business plan. In order to validate our work, we then presented the model to different organizations in various industries (including the SMEs that participated in the case studies). In most cases, the natural reaction of management teams was to position their company along the waves while trying to benchmark themselves, taking into account the current state of advancement of their respective technologies within their industries. One important aspect for management to capture was the variation in technological advancement for the different organizational functions of their company. A large manufacturing company is a good example of this: the technology exploited for design purposes is state-of-the-art and easily configurable to communicate with suppliers. Yet the manufacturing system is ancient and difficult to manage in a supply chain environment. This has incited us to focus our efforts on the most e-commerce-influenced functions of an organization, which are identified in section 4 . To fully grasp the implications of technologies in these functions, we then illustrated a technological wave/function matrix with the most current e-commerce transaction processes identified by the MITI/Andersen Consulting study (see section 2). Displayed in section 6 , the matrix presents electronic transaction processes related to different organizational functions and technological waves, which can provide management with a tool to reflect on their e-commercerelated activities.

\section{Value chain activities}

\section{Background}

In the 1990s, with the advent of technologies such as ERPs, a great deal of activity was concentrated on cross-functional applications within an organization. But ERP vendors like
SAP and Oracle are now focusing on inter-organisational activities such as supply chain management or advanced planning and optimisation. Business-to-business ecommerce will allow organizations to gradually share information with their suppliers and their customers. The question then becomes, where should companies start and how should they organize themselves?

The literature describing the key functions of an organization that does business electronically is scarce. A Japanese Investigating Committee Report produced by the MITI and the Japan Electronic Commerce/CALS Organization (JECALS) has classified business segments into three categories of activities (MITI CALS 1999). According to the study, the vast majority of e-commerce business operations fall under marketing and sales, design and manufacturing, or procurement. Our research has led us to believe that ecommerce transaction processes will be mostly productoriented. A great deal of the efforts now being conducted by major electronic suppliers like Dell or automobile manufacturers like Volvo, BMW and DaimlerChrysler are aimed at supporting integrated product life cycles from design right up to recycling. This requires the gathering of a lot of information on all parts and components of a product throughout its useful life. The information gathering is made possible by the use of product life cycle databases, which support the electronic collaboration between product integrators, suppliers and customers. Birou et al. (1998) singled out three functional areas to demonstrate crossfunctional integration using the product life cycle approach, namely logistics, operations and purchasing.

The integration of suppliers requires major changes to product development processes that may force several key functions within an organization to adjust their processes. Handfield et al. (1999) suggest that, although the design and engineering phases account for a minor fraction of total product costs, it is in those phases that $80 \%$ of the total cost of the product is determined. It is also important to mention that purchased materials often account for over $50 \%$ of the cost of goods sold, reaching as high as $80 \%$ in some industries (Anderson and Katz 1998; Handfield et al. 1999). Consequently, procurement plays a crucial role in product and process development, which includes identifying the right technologies and suppliers, and also leveraging opportunities by taking the leadership of crossfunctional teams (McGinnis and Mele Vallopra 1999). For example, global strategic suppliers for the Boeing 777 project ${ }^{1}$ were integrated in the design process from the beginning, which resulted in the rapid development of the aircraft (Anderson and Katz 1998).

\footnotetext{
${ }^{1}$ The Boeing 777 was entirely designed electronically, linking a supplier base located in Europe, North America, Australia and Asia.
} 
Procurement has evolved from a reactionary and operational function to a more strategic and proactive one. It has been prompted by cross-functional objectives and highly collaborative environments (Segev et al., 2000). Efficient, secure and quick transactional exchanges, along with new planning and forecasting tools and methodologies, have allowed a shift from current tasks to more strategic and value-added activities (Cassivi et al. 2000). As shown in figure 2, procurement activities and competencies, which are now mostly related to transactional buying, will gradually shift to sourcing strategy and analysis, supplier development and new product and process development (Laseter 1998), all of which are much more strategic in nature and which hold important potential benefits for organizations.

\section{Empirical evidence}

According to our analysis, electronic commerce will mainly transform the engineering and design, sales and distribution, and procurement functions. The sales and procurement transaction processes are closely linked while distribution, ${ }^{2}$

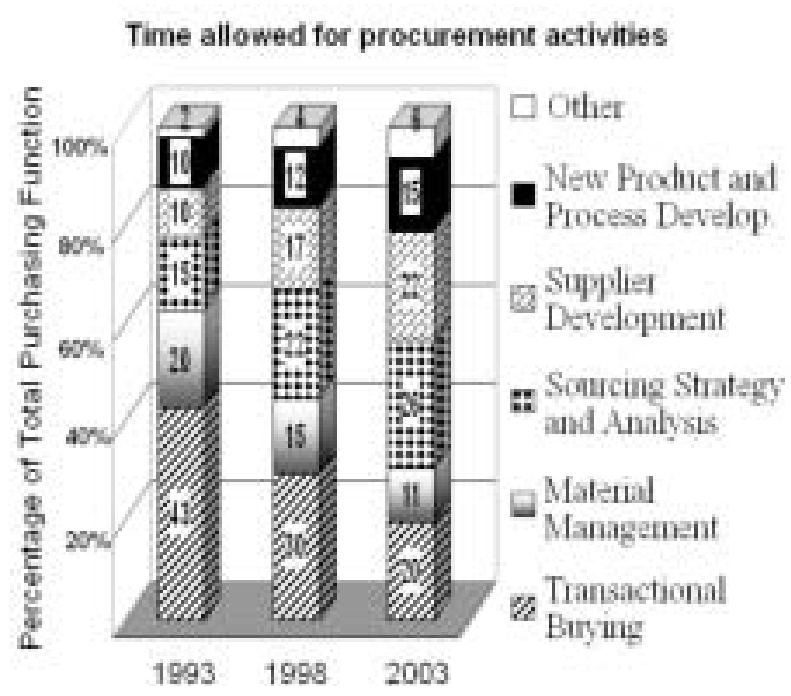

Figure 2. Evolution of procurement.

Source: Adapted from Laseter, T.M., Balanced Sourcing, 1998. which has been identified by specialists as the most important outsourced activity, will require a large amount of information exchange (figure 3). The implementation of design and engineering transaction processes will lead to the second boom in e-commerce.

In the automobile industry, the initial focus will be on procurement and then supply chain planning; it will finally move towards collaborative design and shorter market time cycles (Cooke 2000). Electronic commerce will eventually modify manufacturing functionalities. At present, a majority of shop floors are not computerized. Companies are not ready to share manufacturing data and only the critical information required by procurement is processed electronically. Developments in modular production should greatly enhance the transition to electronic commerce (Van Hoeck and Weken 1998).

\section{Assessment of e-commerce technologies}

\section{Background}

The concepts of electronic commerce and supply chain management are increasingly appealing to most organizations. Reductions in inventory, product development time, time to market, procurement workforce, and the like, have encouraged large companies to adopt advanced technologies in order to achieve the potential savings. Some complex e-commerce transaction processes require the combination of several technologies that must evolve progressively in an integrated environment. Our case studies in the electric/electronic industry led us to develop a technological model that helps large and small companies. The five-wave model accompanies an organization through the different phases of technological integration required to support increasingly complex e-commerce applications. The GartnerGroup (2000) has drawn up a list of technology enablers for supply chain management (Table 1). It sorted

2 This definition of distribution includes external transportation activities.

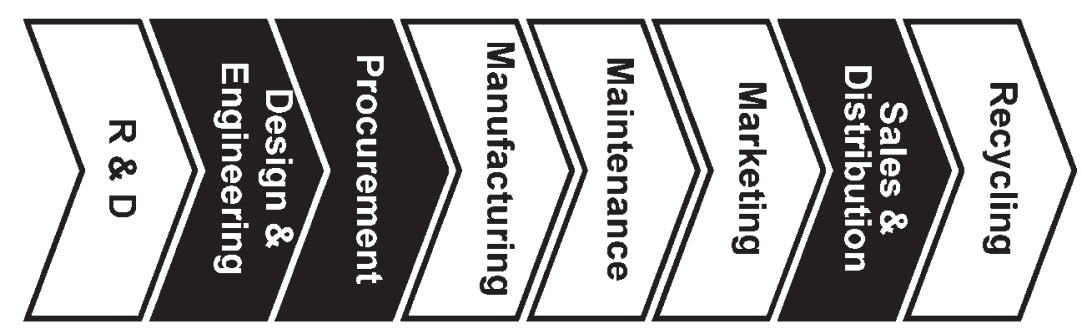

Figure3. The key functions of the value chain presently affected by e-commerce. 
Table 1. Technology enablers.

$\begin{array}{lll}\text { Concept } & \text { Issues } & \text { Technology enablers } \\ \text { Intra-enterprise } & \begin{array}{l}\text { Enterprise functions require information } \\ \text { beyond transaction-oriented data. }\end{array} & \begin{array}{l}\text { ERP, data collection tools, data warehouses, data } \\ \text { mining and service control point groupware. }\end{array} \\ \text { Inter-enterprise } & \begin{array}{l}\text { Suppliers' and customers' needs to be successful. } \\ \text { Extranets, schedule sharing, customer and supplier } \\ \text { self-service applications. }\end{array} \\ & & \begin{array}{l}\text { Supply chain monitoring system, CPFR, EDI, POS } \\ \text { data, extranets, opportunity management systems. }\end{array}\end{array}$

Source: GartnerGroup, 1999.

these technologies into three distinct classes: Intra-, Interand Extended Enterprise. Langenwalter (2000) has also classified supply chain relationships into five stages that show the probable evolution of supply chain integration in relation to its potential effectiveness (Figure 4). Even though technology is not the focus, the development of a supply chain is well presented. At the highest level of effectiveness, a fully integrated supply chain involving technology sharing generates flexible, seamless processes.

\subsection{Empirical evidence}

The proposed five-wave transition model (Figure 5) goes beyond classifying supply chain management or electronic

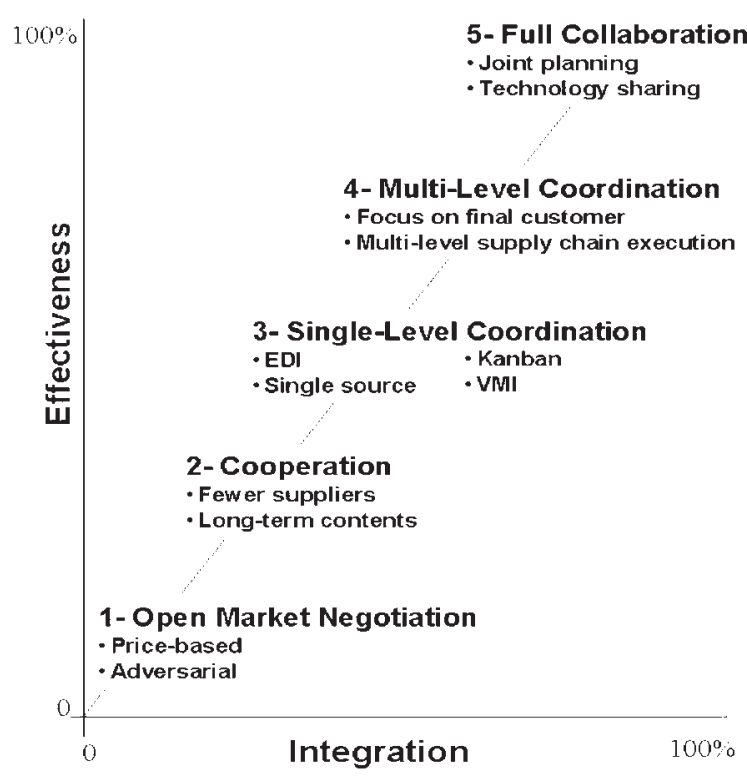

Figure 4. Supply chain relationships.

Source: Langenwalter, G., Enterprise Resources Planning and Beyond, 2000 . commerce concepts, like the two previous examples. It identifies different business-to-business e-commerce needs and specifications and assists firms in detecting their technological and organizational requirements. The highest wave is one where the organization focuses on products, is at ease with international norms and standards, and feels secure dealing electronically with suppliers and clients. We will describe each wave, illustrating some of the related technological and organizational issues.

The first wave consists of the integration of the different internal systems within the organization with various electronic communication tools (Internet, EDI, VPN, etc.). The systems concerned usually relate to simple administrative functions such as invoicing but may also correspond to more complex information exchanges as is the case with production planning activities. These systems support the connection of commercial transactions (sales, procurement, etc.) through simple electronic links. There are numerous examples of activities realized in this first wave. They range from the use of the Internet to regularly inform suppliers or clients of the most recent production plans generated by an MRP system to bidding on a request for quote (RFQ) received electronically through private or public bidding platforms (e.g. www.tpn.com).

The adoption of computerized management systems to coordinate activities within an organization characterizes the second wave. Two technological scenarios are usually favoured by organizations:

1) Integration of independent management systems to form a "best-of-breed" solution.

2) Total or partial adoption of various modules of an ERP tool that can be complemented with specialized applications.

As examples of the second wave, we can mention the adoption of ERP systems in order to manage internal activities right up to the integration of an advanced planning system (APS) into an MRP system to optimise production planning. 
The third wave focuses on automating the capture of information generated during operations (production, warehousing, distribution) and integrating it into the company's management system (ERP, for example). In this operations-oriented stage, a manufacturing company may integrate its shop floor activities (CNC machines, etc.) with its ERP using a manufacturing execution system (MES). The term collaboration has been widely used in e-commerce and supply chain descriptions. It forms the focal point of the fourth wave, which we refer to as Product/Service Value Chain Integration. It centres on the collaboration between various organizations from the same sector to develop products and services through processes or supply chain activities in a virtual mode. At this stage, the customer is also integrated into the value chain, thus facilitating product or service customisation. Examples range from a consortium of organizations using CPFR (collaborative planning, forecasting and replenishment) technology to monitor their supply chain activities to the simultaneous and collaborative design of a virtual prototype (product and manufacturing processes) by a prime contractor and a few strategic suppliers. The fifth wave emphasizes the product life cycle support strategy based on the integration of multi-sector B-to-B platforms. As mentioned previously, it embodies the notion of a virtual enterprise where access to a larger number of subcontractors is facilitated by communication technologies based on specific protocols (e.g. XML, STEP) and where supplier certification (e.g. ISO 14040) becomes a barrier to entry for the supply base. The product life cycle optimisation wave allows a temporary, ad hoc consortium of independent enterprises to pool their respective competencies in order to create a product or support a product line. Very few fifth-wave projects have yet been undertaken; one example is the development of a system that optimises the environmental impact during the design, manufacturing, utilization and recycling phases of a product. This is now being simulated in firms such as BMW.

One important aspect of the model is the possibility to evolve through the waves. The decision for an organization to move on to another wave is often triggered by events, which we will refer to as transitional milestones. Proactive and innovative firms will have a strategic plan with clear transitional milestones to guide them through the process. But most of the time, organizations are confronted by unexpected or undesired milestones that force them to adopt

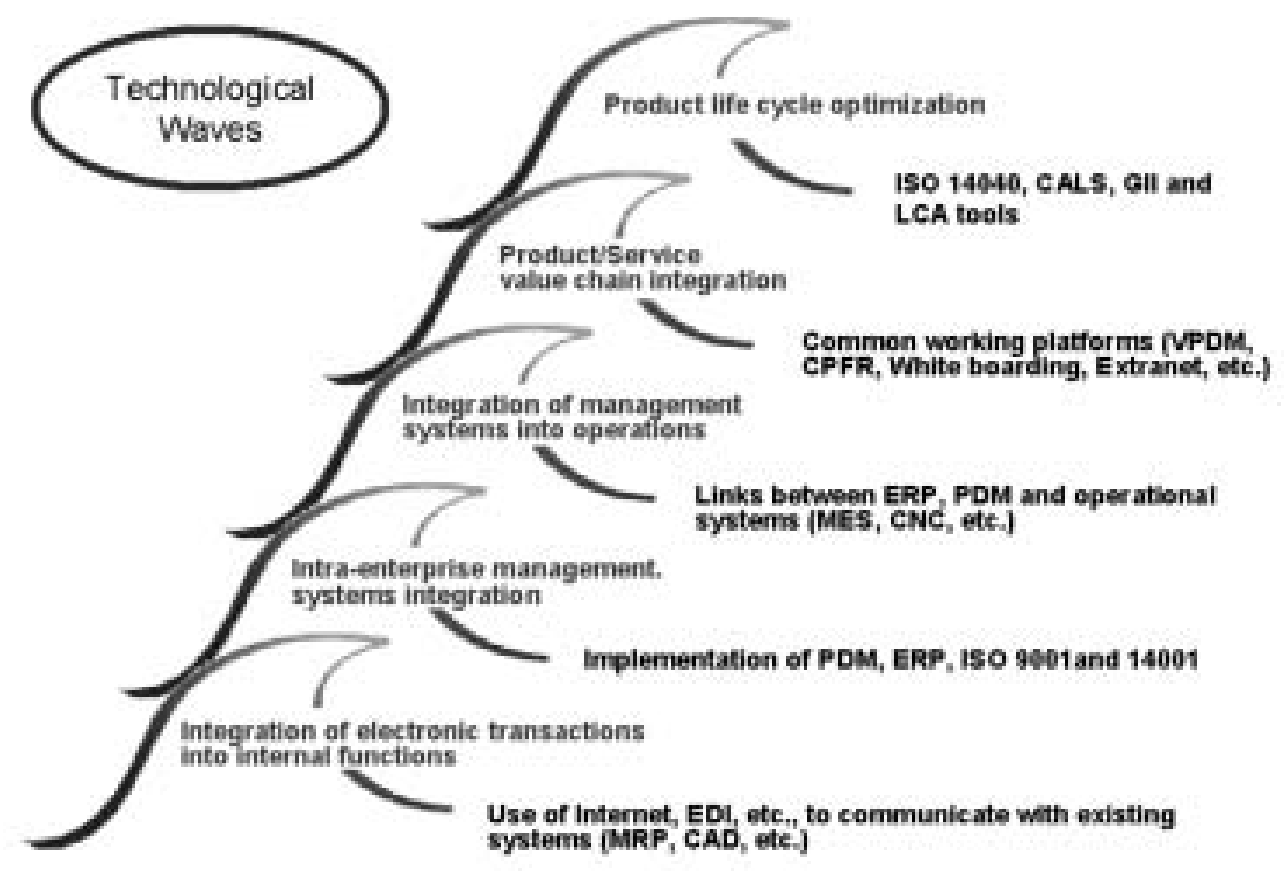

Figure 5. The technological wave transition model.

CAD: Computer-Aided Design

EDI: Electronic Data Interchange

LCA: Life Cycle Assessment

PDM: Product Data Manager
CALS: Continuous Acquisition and Lifecycle Support

ERP: Enterprise Resource Planning

MES: Manufacturing Execution System

VPDM: Virtual Product Development Manager
CNC: Computerized Numerical Control GII: Global Information Infrastructure MRP: Material Resource Planning CPFR: Collaborative Planning, Forecasting and Replenishment 
Louis A. Lefebvre, Luc Cassivi and Élisabeth Lefebvre

Table 2. Possible transitional milestones from the 1 st to the 2 nd wave.

Type

Market

Organizational

Political-economic

Sectorial

Technological
Transitional milestone

Emerging opportunities in e-commerce such as new products or services

Mergers or acquisitions of 2nd- wave organizations

Multi-country or international financial reporting

Sectorial or industry pressures

Evolution of web-based ERP functionalities new technologies very rapidly, without having time to prepare adequately. We have identified five types of transitional milestones (market, organizational, political-economic, sectorial and technological) that can influence the technological plan of an organization. Examples of transitional milestones that have prompted some organizations to jump from the first wave (simple electronic communications) to the second (ERP) are shown in table 2.

\section{The transaction processes}

The wave model implicitly assumes that technologies will affect certain organizational functions and activities. Bridging these two dimensions forms a conceptual framework in which electronic commerce strategies can be developed. Evidently, these strategies are often revealed through transaction processes, which are crucial to the flow of information within and between organizations.

To illustrate this context, we aligned the five technological waves horizontally and the selected functions vertically in the matrix shown in figure 6 . In order to demonstrate the value of the matrix, we integrated the e-commerce transaction processes identified in the MITI study described in section 2 . Three of the twelve transaction processes were selected to demonstrate the model. These three processes are very different and yet complementary with respect to the organizational function concerned and the technology required.

The following illustrates how each transaction stands in the matrix and shows its potential evolution as we move through the different waves.

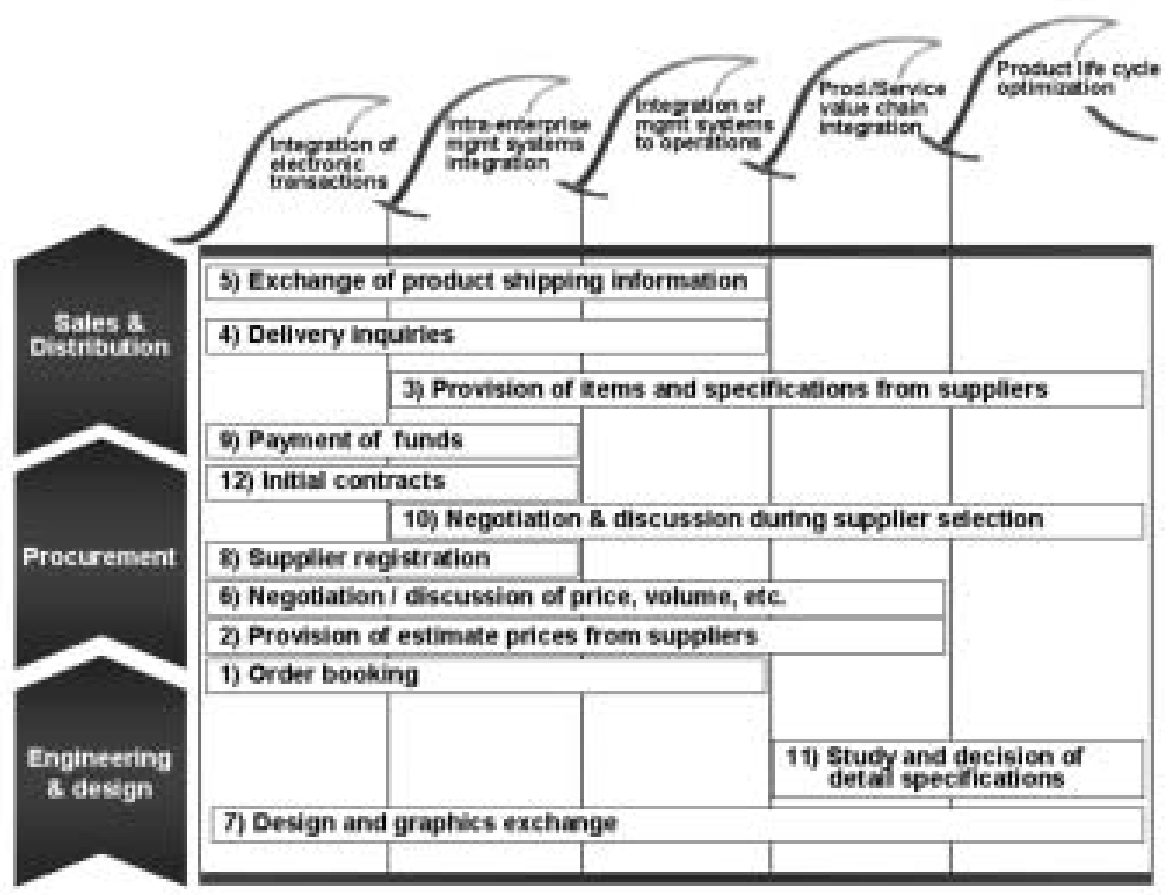

Figure 6. Technology / function matrix. 


\section{Provision of estimate prices from suppliers}

This transaction involves purchasers. It occurs very frequently in supply chains and covers four technological waves since the methods used by the procurement department to purchase a product/service differ in complexity. A brief description of this transaction across different technological scenarios follows:

1st wave: Obtaining a price (and CAD file) through the Internet.

2nd wave: Being able to easily obtain information on a product or service (bid history, last price paid, etc.) and to compare it those of competitors.

3rd wave: "Make or buy" decisions requiring faster feedback from the shop floor and/or distribution centre.

4th wave: Collaborating on product development in order to get quicker, more accurate prices on, for example, custom-made products and special demands.

\section{Delivery inquiries}

This transaction involves the sales and distribution workforce. It can be carried out automatically through various systems:

1st wave: Exploiting electronic communications such as e-mail to minimize costs and errors when compared to fax or telephone communications.

2nd wave: Processing inquiries by accessing information systems (e.g. ERP) without any human intervention from the seller/manufacturer (through the use of specific APIs).

3rd wave: Allowing the transmission of critical information to key customers and suppliers by:

(i) Linking a Global Positioning System (GPS) to an information system to trace a fleet of trucks.

(ii) Monitoring the manufacturing activities of an organization with the help of an inventory control system on the shop floor.

\section{Study and decision of detail specifications}

This transaction involves the design and engineering departments. It entails precise details that are very frequently listed on a CAD file or other types of electronic blueprints. To be effective, this activity must be executed in a real-time collaborative environment:

4th wave: Developing products on common platforms (e.g. VPDM) through the collaboration of engineers and design specialists (from various organizations). 5th wave: Understanding the product life cycle by involving the different stakeholders (designer, manufacturer, recycler, distributor, etc.) that may influence the development of a product.

\section{Conclusion and future research}

This research project started in the early days of electronic commerce in 1997, when e-commerce transaction processes were mainly exploited by large organizations. Although the project is very broad in that it touches upon the study of numerous functions in firms in a specific sector of industrial activity known to be relatively advanced in e-commerce applications, our objectives have been to understand the global e-commerce picture, to identify the emerging technologies and to create a conceptual framework using a technological transition model. The wave model was further illustrated through a technology function matrix identifying different functional processes and their evolution over the waves.

In the future, we hope to expand the model to other organizational functions and e-commerce functionalities as they become more diffused in organizational settings. Technologies will most certainly evolve over time, offering new opportunities but also requiring new organizational capabilities and skills. Monitoring these changes will become a constant challenge for researchers and organizations.

\section{References}

Anderson, M.G. and P.B. Katz, 1998. Strategic Sourcing. International Journal of Logistics Management. Vol. 9, No. 1, pp. 1-13.

Bakos, J.Y. and E. Brynjolfsson, 1993. Information Technology, Incentives and the Optimal Number of Suppliers. Journal of Management Information Systems. Vol.10, No. 2, pp. 37-54.

Birou, L.M., S.E. Fawcett and G.M. Magnan, 1998. The Product Life Cycle: A Tool for Functional Strategic Alignment. International Journal of Purchasing and Materials Management. Spring, pp. 37-51.

Cassivi L., L.A. Lefebvre and E. Lefebvre, 2000. Multi-Layered Collaborative Procurement Planning and Optimisation. Proceedings of the 2000 IEEE International Engineering Management Conference. August 13-15, Albuquerque, NM, pp. 278-283.

Collins, R. and K. Bechler, 1999. Outsourcing in the Chemical and Automotive Industries: Choice or Competitive Imperative? The Journal of Supply Chain Management, Fall, pp. 4-11.

Cooke, J.A., 2000. The Dawn of Supply Chain Communities. Logistic Management and Distribution Report. February, pp. 44-48.

Cox, A., J. Sanderson and G. Watson, 2000. Wielding Influence. Supply Management. April 6, pp. 31-33. 
GartnerGroup Report, March 1999. Supply Chain Management: Optimizing the Path from Supplier to Customer.

Groves, G. and V. Valsamakis, 1998. Supplier-Customer Relationships and Company Performance. The International Journal of Logistics Management. Vol. 9, No. 2, pp. 51-64.

Handfield, R.B., G.L. Ragatz, K.J. Petersen and R.M. Monczka, 1999. Involving Suppliers in New Product Development. California Management Review. Vol. 42, No. 1, pp. 59-82.

Heikkilä, J. and T.E. Vollmann,1999. Do Telecommunications Operators Understand Demand Chain Efficiency? International Institute for Management Development.

HIDC -Holland International Distribution Council, The Netherlands, 1998. Worldwide Logistics: The Future of Supply Chain Services.

Industry Directions and Syncra Systems, 2000. The Next Wave of Supply Chain Advantage.

Langenwalter, G., 2000. Enterprise Resources Planning and Beyond: Integrating Your Entire Organization. Boca Raton, St. Lucie Press.

Laseter, T.M., 1998. Balanced Sourcing: Cooperation and Competition in Supplier Relationships. San Francisco, Jossey-Bass.

Lefebvre, L.A., E.Lefebvre and P. Mohnen (eds.), 2001. Doing business in the knowledge based economy, Kluwer Academic Publishers, Boston.

McGinnis, M.A. and R. Mele Vallopra, 1999. Purchasing and Supplier Involvement in Process Improvement: A Source of Competitive Advantage. Journal of Supply Chain Management. Fall, pp. 42-50.
Miles, M and A. Huberman, 1994. Qualitative Data Analysis: An expanded Sourcebook. Second edition, Newbury Park, CA: Sage.

Ministry of International Trade and Industry of Japan, March, 1999. Electronics Policy Division, Machinery and Information Industries Bureau. Size of Market Study for Electronic Commerce.

Ministry of International Trade and Industry of Japan and the Japan Electronic Commerce/CALS Organization, March 1999. Current Status of B-to-B Electronic Commerce in Japan.

OECD Policy Brief no.1, 1997 - Electronic Commerce.

OECD Workshop, 1999. Defining and Measuring Electronic Commerce. April 21.

PricewaterhouseCoopers, 1999. Shaping the Value Chain for Outstanding Performance. Global Logistics Forum.

Schorr, J.E., 1998. Purchasing in the 21st Century: A Guide to Stateof-the-Art Techniques and Strategies. New York, Wiley.

Segev, A., J. Gebauer and F. Färber, February 2000.The Market for Internet-Based Procurement Systems - Part 1: The Context of Procurement Transformation. Fisher Center for Information Technology and Marketplace Transformation Research Report.

Smeltzer, L.R. and S.P. Siferd, 1998. Proactive Supply Management: The Management of Risk. International Journal of Purchasing and Materials Management. Winter, pp. 38-45.

Van Hoeck, R.I. and H.A.M. Weken. 1998. The Impact of Modular Production on the Dynamics of Supply Chains. The International Journal of Logistics Management, Vol. 9, No. 2, pp. 35-50.

Yin, R.K., 1994. Case Study Research: Design and Methods, Second edition, Sage Publication Inc., Thousand Oaks.

\section{Appendix 1: Projected growth in B-to-B e-commerce}

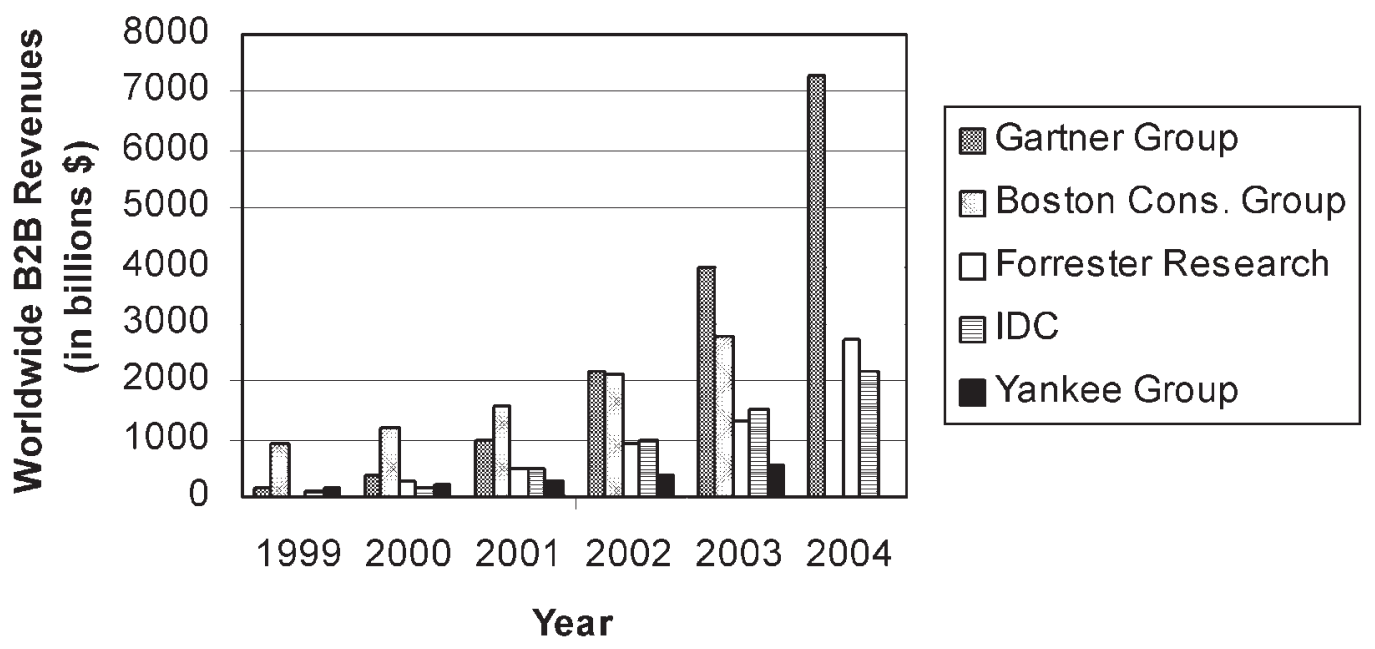

Source: Gartner Group (January 2000), Boston Consulting Group (December 1999), Forrester Research (February 2000), International Data Corporation (April 2000) and Yankee Group (March 1999). 